BMJ Open Ophthalmology

\title{
Eyelid skin trichilemmoma and underlying local malignancy: is an aggressive treatment necessary?
}

\author{
Christine Anggun Putri (D) ,' Hardeep Singh Mudhar, ${ }^{2}$ Adam Meeney, ${ }^{2}$ \\ Jennifer $\mathrm{H} Y \operatorname{Tan}^{1}$
}

To cite: Putri CA, Mudhar HS, Meeney A, et al. Eyelid skin trichilemmoma and underlying local malignancy: is an aggressive treatment necessary? BMJ Open Ophthalmology 2020;5:e000513. doi:10.1136/ bmjophth-2020-000513

Received 11 May 2020 Revised 29 May 2020 Accepted 8 June 2020

\section{Check for updates}

\section{C) Author(s) (or their} employer(s)) 2020. Re-use permitted under CC BY-NC. No commercial re-use. See rights and permissions. Published by BMJ.

${ }^{1}$ Department of Ophthalmology, Royal Hallamshire Hospital, Sheffield, UK

${ }^{2}$ National Specialist Ophthalmic Pathology Service (NSOPS), Department of Histopathology, Royal Hallamshire Hospital, Sheffield, UK

Correspondence to Dr Christine Anggun Putri; christineputri@doctors.org.uk

\section{ABSTRACT}

Objective Trichilemmoma is a benign tumour derived from the outer root sheath of hair follicles. Trichilemmoma can be associated with basal cell carcinoma (BCC), either as a collision lesion or from malignant transformation. This study evaluates malignancy associated with eyelid trichilemmoma and principles of treatment.

Methods and analysis Retrospective study involving biopsy-proven eyelid trichilemmoma cases over 14 years encountered at a tertiary referral centre. Presenting features, differential diagnosis, type and number of operations required and histopathological features including coexisting BCC were analysed.

Results We identified 36 cases with an average age of 66 years. The clinical differential diagnoses were mainly BCC (44\%), papilloma (36\%) and squamous cell carcinoma (SCC) (3\%). Three patients (8\%) had trichilemmoma with associated BCC. Of the 19 cases (53\%) of trichilemmomas without BCC with equivocal surgical margins, seven patients (19\%) opted for further excision while 12 patients (33\%) opted for observation and were discharged. A patient re-presented two years later with invasive BCC. Overall, $11 \%$ of our biopsy-proven eyelid trichilemmoma cases were associated with BCC

Conclusion Patients should be informed that a proportion of incompletely excised eyelid trichilemmomas may conceal underlying BCC. Therefore, further surgery to achieve clear surgical margins should be offered. Patients who opt for observation should be offered 6-monthly follow-up for three to five years. Alternatively, they can be discharged with advice to report any recurrence of lumps, skin changes or loss of lashes at the site of previous lesion.

\section{INTRODUCTION}

Trichilemmoma is a benign tumour derived from the outer root sheath of the hair follicle. It was first described by Headington and French in 1962. ${ }^{1}$ Trichilemmoma may occur anywhere in the body, with the vast majority occurring on the face and nose, followed by eyebrow and eyelids being the most common locations. ${ }^{2}$ Trichilemmoma has a very variable clinical appearance thus mimicking other benign or malignant skin lesions such as basal cell carcinoma (BCC) or squamous cell carcinoma (SCG). ${ }^{34}$ Desmoplastic trichilemmoma

\section{Key messages}

What is already known about this subject?

- Trichilemmoma is a benign tumour derived from the outer root sheath of the hair follicle which can occur in association with basal cell carcinoma (BCC).

\section{What are the new findings?}

$11 \%$ of eyelid trichilemmoma is associated with BCC.

How might these results change the focus of research or clinical practice?

- Complete excision of trichilemmoma is strongly advised as incompletely excised trichilemmoma may conceal underlying malignancy.

> Patients who opt for observation for incompletely excised eyelid trichilemmoma have to be warned on the risk of coexisting BCC. They should be offered 6 -monthly follow-up for three to five years with sequential clinical photography and examination. Alternatively, they can be discharged with advice to report any signs of recurrence of the lesion, skin changes or loss of lashes especially at the site of previous trichilemmoma lesion.

(DT), a variant of trichilemmoma, is known to occur in association with BCC. ${ }^{5}$ Due to clinical and histopathological resemblances between trichilemmoma and other skin malignancies, making the correct diagnosis of trichilemmoma can sometimes be challenging. To our knowledge, there is no published data on the frequency of BCC with eyelid trichilemmoma. The purpose of this study is to evaluate the association between eyelid trichilemmoma and BCC in our patient population and to evaluate our treatment strategiesespecially for incompletely excised trichilemmomas.

\section{MATERIALS AND METHODS}

We used the histopathology database of our local histopathology department to retrospectively search for biopsy results coded as 'trichilemmoma' from year 2004 to 2018 . The histopathological reports of trichilemmoma cases identified were reviewed for clearance 


\begin{tabular}{lcc}
$\begin{array}{l}\text { Table } 1 \\
\text { cases }\end{array}$ & Baseline characteristics of 36 trichilemmoma \\
\hline Demographics & $\mathbf{n}$ & $\%$ \\
\hline $\begin{array}{l}\text { Gender } \\
\text { Male }\end{array}$ & 14 & 39 \\
$\quad$ Female & 22 & 61 \\
\hline Ethnicity & & \\
$\quad$ Caucasian & 36 & 100 \\
\hline Age group (range 43-85 years) & & \\
$\quad 41-50$ years & 3 & 19 \\
\hline 51-60 years & 7 & 39 \\
\hline $61-70$ years & 14 & 25 \\
\hline $71-80$ years & 9 & 8 \\
\hline $81-90$ years & 3 & 6 \\
\hline Relevant ocular history & & \\
\hline Previous trichilemmoma & 2 & \\
\hline
\end{tabular}

of margins and presence of coexisting BCC. Electronic patient record, Medisoft (Medisoft, Leeds, UK) and patient case notes were reviewed to collect data on presenting features, operation required and subsequent follow-up.

Patients or the public were not involved in the design, conduct, reporting or dissemination plans of our research.

\section{RESULTS}

From 6169 eyelid specimens that were analysed over 14 years, we identified 36 patients with trichilemmoma from the database. This gives a frequency of $0.006 \%$. All patients in our cohort were of Caucasian race with average age of 66 years old and the majority were women. Baseline characteristics are highlighted on table 1.

Patients presented with a variety of symptoms including eyelid lumps $(n=30,83 \%)$, loss of lashes $(n=3,8 \%)$ and a non-healing lesion $(\mathrm{n}=1,3 \%)$. In four cases, the presenting features were not recorded. Some of patients presented with multiple features. The majority of prebiopsy diagnoses based on clinical features alone were BCC $(44 \%)$ and papilloma $(36 \%)$. Other diagnoses

\begin{tabular}{|c|c|c|}
\hline Differential diagnosis & $\mathbf{n}$ & $\%$ \\
\hline $\mathrm{BCC}$ & 16 & 44 \\
\hline Papilloma & 13 & 36 \\
\hline SCC & 1 & 3 \\
\hline Actinic keratosis & 1 & 3 \\
\hline Trichilemmoma & 1 & 3 \\
\hline Sebaceous cyst & 1 & 3 \\
\hline Unknown & 3 & 8 \\
\hline
\end{tabular}

BCC, basal cell carcinoma; SCC, squamous cell carcinoma.

\section{Marginal clearance in trichilemmoma cases without coexisting BCC ( $n=33)$}
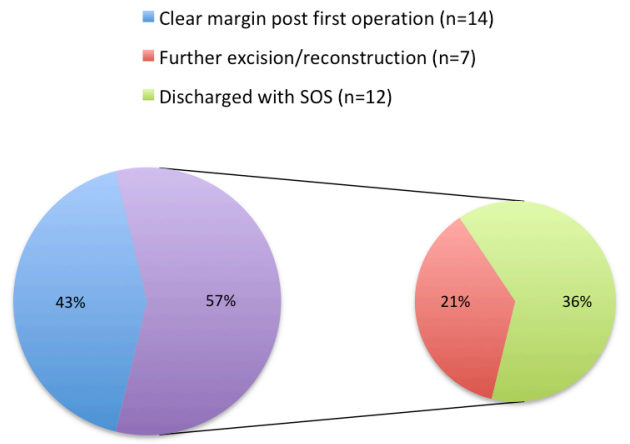

Figure 1 In those without coexisting BCC, 19 patients $(57 \%)$ did not achieve clear surgical margin for trichilemmoma following the first operation and only seven patients $(21 \%)$ underwent further surgical intervention to achieve clear margin. Twelve patients (36\%) opted to be discharged without clear surgical margin. SOS, Self-referral of symptoms.

include SCC, actinic keratosis, trichilemmoma and sebaceous cyst (table 2).

Based on the first operation which was usually an excision or a biopsy-type procedure, 33 patients (92\%) had trichilemmoma without BCC component and three patients $(8 \%)$ had trichilemmoma with coexisting BCC. These three patients underwent further surgery to achieve surgical margin clearance. In those without coexisting BCC, 14 patients (43\%) achieved clear surgical margin following the first operation while 19 patients (57\%) did not. Among these patients, seven patients (21\%) opted for further operation for surgical margin clearance as well as for further reconstruction. Twelve patients $(36 \%)$ opted to be discharged with incompletely excised trichilemmoma (figure 1).

A patient who was discharged with incompletely excised trichilemmoma returned two years later with an enlarging nodule and telangiectasia on the site of previous trichilemmoma. The patient underwent staged excision with wedge excision and reconstruction, with histopathology results confirming nodular BCC. Previous trichilemmoma histology results of the same patient were reviewed and this confirmed positive CD34 staining with negative BerEP4 with desmoplastic foci centrally and toward the base. This immunohistochemical profile strongly favours a trichilemmoma. Therefore, according to our database with 14 years of data, $11 \%$ of our patients with trichilemmoma had coexisting BCC.

Here are the descriptions of the other three cases of trichilemmoma coexisting with BCC.

\section{Case 1}

A 85-year-old Caucasian man presented with a very slowly enlarging left lower eyelid lump measuring $4 \mathrm{~mm}$ with minimal loss of lashes. This lesion was clinically 


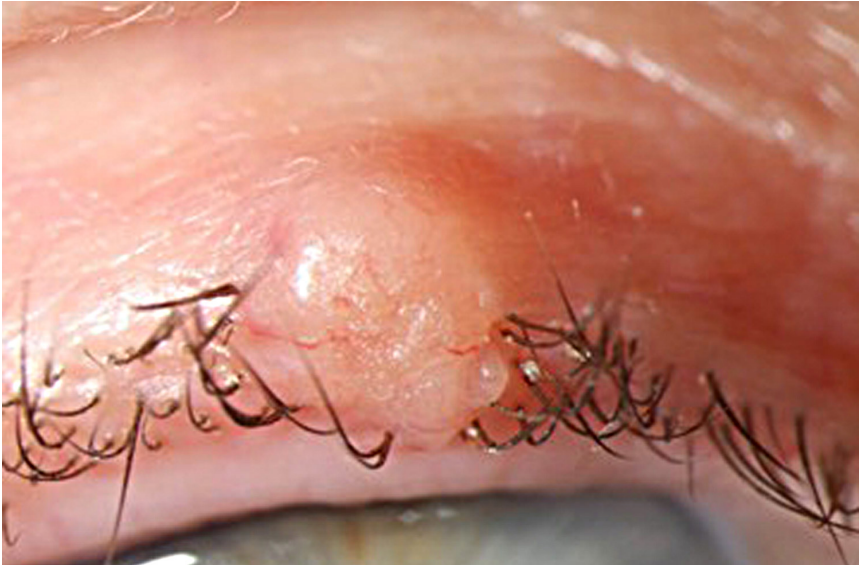

Figure 2 This trichilemmomal lesion displayed clinical features of BCC such as pearly rolled edge, telangiectasia with loss of lashes and was subsequently proven to coexist with BCC.

suspicious of BCC. He underwent a wedge excision with $3 \mathrm{~mm}$ margin and direct closure. Histology showed DT and coexisting BCC with clear excision margin. He has not reported recurrence of lesion since then.

\section{Case 2}

A 78-year-old Caucasian woman presented with an enlarging upper eyelid lump on the site of previously biopsied lump of unknown nature. This pearly lesion with rolled edge and telangiectasia was suspicious of BCC; therefore, a punch biopsy was performed (figure 2). Histological and immunohistochemistry studies with CD34 and BerEP4 showed a DT with a micronodular and infiltrative BCC. This area BCC was incompletely excised. The patient underwent further surgeries including an anterior lamellar excision and wedge excision to achieve clear surgical margin and subsequent reconstruction with direct closure. Analysis across all the specimens revealed that this lesion was predominantly a DT (95\%) with minor BCC component.

\section{Case 3}

A 62-year-old Caucasian woman presented with a right lower lid persistent lump. This was suspected to be a papilloma and an excisional biopsy of the lump was performed. This showed an incompletely excised DT with an atypical basaloid component toward the edge of lesion. She then underwent an anterior lamellar excision, and this confirmed that the basaloid component was a superficial type BCC within a trichilemmoma (figure 3 ). As the excision of this BCC was not guaranteed, she underwent yet another combined anterior lamellar excision and reconstruction. Following the third surgery, histopathological results showed clear surgical margin.

\section{DISCUSSION}

DT is a rare benign skin tumour derived from the outer sheath of the hair follicle. This occurs with a frequency of about $0.003 \%$ of all skin tumours. ${ }^{6}$ This correlates with

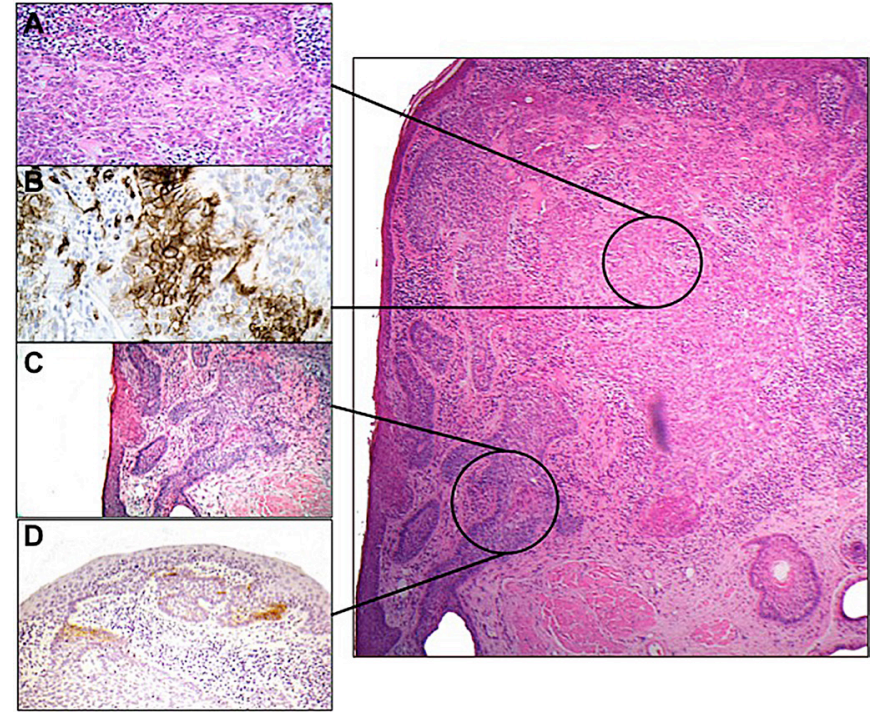

Figure 3 Image on the right displays H\&E-stained section showing DT indicated by the top black circle and BCC indicated by the lower black circle. (A) H\&E. Higher power of DT, showing strands of tumour cells surrounded by pink basement membrane-like material. (B) CD34 immunohistochemistry staining showing positivity in DT (brown colour=positive staining). (C) H\&E of higher power of BCC. (D) BerEP4 immunohistochemistry staining showing focal positivity of BCC (brown colour=positive staining) (Images adapted from Ung et $\left.a\right|^{15}$ ).

our 14 years of data; trichilemmoma is uncommon as it comprised $0.006 \%$ of all eyelid specimens encountered. Trichilemmoma is more prevalent in men, even though our data showed more females affected $(61 \%) .{ }^{6}$ Trichilemmoma is most commonly found in the Caucasian population in the sixth decade of life. ${ }^{7}$ We found a similar racial and age distribution in our series; all of Caucasian race and majority being in their $60 \mathrm{~s}$.

Typically, this lesion appears as a slow-growing, solitary, hard, annular lesion, 5-10 $\mathrm{mm}$ in size, with raised border and depressed centre. Not uncommonly, trichilemmoma may also have a papular, nodular, dome-shaped, papillomatous, verrucous or cutaneous-horn appearances. They may be erythematous, skin-coloured, keratotic, smooth and some even have central ulceration. Because of its clinically highly variable appearances, trichilemmoma is often misdiagnosed as other benign or malignant skin lesions such as BCC (nodular or morphoeic forms), SCC, follicular keratosis or cutaneous horn. ${ }^{3}$ Our cohort of patients displayed various clinical appearances and this is reflected on our variable clinical differential diagnoses (SCC, BCC, papilloma, actinic keratoses and sebaceous cyst). Multiple trichilemmomas that mainly involve the face are features of Cowden's disease which is a multiple hamartoma syndrome with increased risk of carcinoma of breast and thyroid. ${ }^{8}$

Histopathological misdiagnosis of trichilemmoma is not uncommon and patients may be subjected to unnecessary extensive surgery and anxiety surrounding the diagnosis of malignant skin condition. Histopathological 
appearances of trichilemmoma may resemble tricholemmal carcinoma, SCC, trichoepithelioma and inverted follicular keratosis. Illueca et al described the use of CD34 immunohistochemistry for DT to differentiate it from other tumours with desmoplastic differentiation particularly BCC. BerEP4 stains BCC but not DT and CD34 stains DT but not BCC. ${ }^{9}$ Occasionally, the CD34 staining of DT may be focal. Careful analysis of histological appearances coupled with immunohistochemisty is essential in making the correct diagnosis.

The aetiology of trichilemmoma is not fully understood. Due to similar histological and clinical appearance to verruca vulgaris, it was suggested that trichilemmoma may be caused by human papillomavirus. ${ }^{3610}$ However, subsequent study did not support this. ${ }^{11}$ A tumour suppressor gene, PTEN/MMAC1, has been associated with aetiology of trichilemmoma in Cowden's disease. ${ }^{12}$

In the published literatures, the management of trichilemmoma is non-specific including shave excision, curretage, 5-fluorouracil and complete excision. ${ }^{13}$ Depending on the clinical suspicion of the lesion, our standard practice is to perform a biopsy, complete excision or staged excision and reconstruction. Mohs micrographic surgery is an alternative surgical management for trichilemmoma. ${ }^{14}$ Mohs micrographic surgery is particularly useful for trichilemmoma of the face as it provides maximum tissue-sparing benefit and excellent cosmetic results. No patient in our case series underwent Mohs micrographic surgery and this is due to service provision in our department.

It was previously reported that BCC can occur in association with DT. ${ }^{5}$ Such cases may represent primary DT with contiguous BCC or primary BCC with tricholemmal differentiation. ${ }^{15}$ Histopathological analysis across specimens is essential in determining the nature of the lesion. This is illustrated in case 2, where the analysis across specimens showed that majority of lesion was DT $(95 \%)$ with a minor BCC component. Therefore, case 2 represents a DT with focal transformation to BCC or coexistence with BCC, rather than primary BCC with tricholemmal differentiation. Trichilemmoma is derived from the external sheath cells of pilosebaceous units. ${ }^{16}$ BCC is a malignant tumour of trichoblast differentiation and possibly of follicular derivation. ${ }^{17}$ Therefore, coexistence of the two lesions can be explained by their hair follicle origins. DT has also been reported occurring within a naevus sebaceous. $^{18} 19$

Following the first operation, three patients $(8 \%)$ had trichilemmoma with associated BCC. In those without coexisting BCC, 12 patients (36\%) opted to be discharged with incompletely excised trichilemmoma because of the benign nature of the lesion. A patient (3\%) from this cohort, returned two years later with BCC. This highlights that an incomplete excision of trichilemmoma can give a false sense of reassurance. For incompletely excised trichilemmoma, we strongly advocate offering further surgery to achieve clear surgical margins to ensure that potential coexisting local malignancy is not left untreated. In our experience, elderly patients tend to opt for observation instead of multiple surgeries to achieve clear surgical margins for this benign lesion. Out of 36 cases of biopsy-proven eyelid trichilemmoma, we identified four cases with coexisting BCC, thus giving a frequency of $11 \%$. Those who opt for observation should be warned of the risk of coexisting BCC. Similar to patients with BCC, this group of patients should be offered 6-monthly follow-up for three to five years with sequential clinical photography and examination. Alternatively, they can be discharged with advice to report any signs of recurrence of the lesion, skin changes or loss of lashes especially at the site of previous trichilemmoma lesion. This allows for better workload prioritisation by healthcare providers.

\section{CONCLUSION}

Trichilemmoma can mimic and coexist with malignant skin conditions such as BCC. Histological and immunochemistry studies are essential in making a diagnosis. We strongly advocate the complete excision of trichilemmoma to ensure excision of potential coexisting BCC. Patients who opt for conservative management for incompletely excised trichilemmoma have to be warned on the risk of coexisting BCC. They should be offered regular follow-up in clinic or be discharged with advice to report any signs of recurrence of the lesion, skin changes or loss of lashes especially at the site of previous trichilemmoma lesion.

\section{Collaborators Not applicable.}

Contributors CAP involved in the planning of the study, data collection and analysis, review of the literature, manuscript drafting and final approval of the manuscript. HSM involved in data collection and analysis, final approval of the manuscript. AM involved in data collection and analysis. JHYT involved in conception and planning of the study, review of the literature and final approval of the manuscript.

Funding The authors have not declared a specific grant for this research from any funding agency in the public, commercial or not-for-profit sectors.

Competing interests None declared.

Patient consent for publication Not required.

Provenance and peer review Not commissioned; internally peer reviewed.

Data availability statement All data relevant to the study are included in the article or uploaded as supplementary information.

Open access This is an open access article distributed in accordance with the Creative Commons Attribution Non Commercial (CC BY-NC 4.0) license, which permits others to distribute, remix, adapt, build upon this work non-commercially, and license their derivative works on different terms, provided the original work is properly cited, appropriate credit is given, any changes made indicated, and the use is non-commercial. See: http://creativecommons.org/licenses/by-nc/4.0/.

ORCID iD

Christine Anggun Putri http://orcid.org/0000-0002-0989-2784

\section{REFERENCES}

1 Headington JT, French AJ. Primary neoplasms of the hair follicle. histogenesis and classification. Arch Dermatol 1962;86:430-41.

2 Hidayat AA, Font RL. Trichilemmoma of eyelid and eyebrow. A clinicopathologic study of 31 cases. Arch Ophthalmol 1980;98:844-7.

3 Hunt SJ, Kilzer B, Santa Cruz DJ. Desmoplastic trichilemmoma: histologic variant resembling invasive carcinoma. J Cutan Pathol 1990;17:45-52. 
4 Tellechea O, Reis JP, Domingues JC, et al. Monoclonal antibody Ber EP4 distinguishes basal-cell carcinoma from squamous-cell carcinoma of the skin. Am J Dermatopathol 1993;15:452-5.

5 Crowson AN, Magro CM. Basal cell carcinoma arising in association with desmoplastic trichilemmoma. Am J Dermatopathol 1996;18:43-8.

6 Tellechea O, Reis JP, Baptista AP. Desmoplastic trichilemmoma. Am J Dermatopathol 1992;14:107-14.

7 Möhlenbeck FW. [Trichilemmoma. A study of 100 cases]. Z Hautkr 1974;49:791-5.

8 Brownstein $\mathrm{MH}$, Mehregan AH, Bilowski JB. Trichilemmomas in Cowden's disease. JAMA 1977;238:26.

9 Illueca C, Monteagudo C, Revert A, et al. Diagnostic value of CD34 immunostaining in desmoplastic trichilemmoma. J Cutan Pathol 1998;25:435-9.

10 Phillips ME, Ackerman AB. "Benign" and "malignant" neoplasms associated with verrucae vulgares. Am J Dermatopathol 1982;4:61-84.

11 Leonardi CL, Zhu WY, Kinsey WH, et al. Trichilemmomas are not associated with human papillomavirus DNA. J Cutan Pathol 1991;18:193-7.
12 Nelen MR, van Staveren WC, Peeters EA, et al. Germline mutations in the PTEN/MMAC1 gene in patients with Cowden disease. Hum Mol Genet 1997;6:1383-7.

13 Rodgers IR JF, Hidayat AA. Eyelid tumours of apocrine, eccrine and pilar origins. In: Albert DM, ed. Principles and practice of ophthalmology. Philadelphia: WB Saunders, 2000: 3422.

14 Schweiger E, Spann CT, Weinberg JM, et al. A case of desmoplastic trichilemmoma of the lip treated with Mohs surgery. Dermatol Surg 2004;30:1062-4.

15 Ung T, Tan JH, Mudhar H. Three patients with desmoplastic tricholemmoma with an incidental histological surprise impacting on management. Br J Ophthalmol 2012;96:461-2.

16 Tsai J-H, Huang W-C, Jhuang J-Y, et al. Frequent activating HRAS mutations in trichilemmoma. Br J Dermatol 2014;171:1073-7.

17 Sellheyer K. Basal cell carcinoma: cell of origin, cancer stem cell hypothesis and stem cell markers. Br J Dermatol 2011;164:696-711.

18 Rosón E, Gómez Centeno P, Sánchez-Aguilar D, et al.

Desmoplastic trichilemmoma arising within a nevus sebaceus. Am J Dermatopathol 1998;20:495-7.

19 Lee CA, Kang SJ, Jeon SP, et al. Simultaneous development of three different neoplasms of Trichilemmoma, desmoplastic Trichilemmoma and basal cell carcinoma arising from nevus sebaceus. Arch Craniofac Surg 2017;18:46-9. 